DOI 10.37882/2223-2982.2021.01.24

\title{
КОМБИНИРОВАННОЕ ОБУЧЕНИЕ (ВLENDED-LEARNING) КАК ЭФФЕКТИВНАЯ МЕТОДИКА В СФЕРЕ ЯЗЫКОВОГО ОБРАЗОВАНИЯ
}

\section{BLENDED-LEARNING AS AN EFFECTIVE METHOD IN THE SPHERE OF LANGUAGE EDUCATION}

A. Perov

Summary: This article is intended to reveal the features of the use of combined education in the environment of a Russian university. As an innovative teaching model that involves a combination of traditional and new approaches in foreign language education, it has shown its effectiveness in today's conditions. The article illustrates the capabilities of the methodology under consideration, describes possible technologies for its implementation in the educational space of a Russian university. The author of the work concludes that blended learning can become a starting point in further reforming university language education in Russia.

Keywords: combined education, blended-learning, foreign language, non-linguistic university.
$\mathrm{B}$ связи с современными событиями, происходящими на глобальной арене, встали вопросы реформирования и практически полной перестройки образовательного процесса, в том числе и в системе высшего образования. Проблема сохранения здоровья учащихся и профессорско-преподавательского состава, а также требования по сокращению контактов среди населения обострили интерес педагоговпрактиков к методикам обучения иностранному языку с использованием дистанционных образовательных технологий. Одним из таких способов взаимодействия с учебной аудиторией стало так называемое комбинированное обучение (blended-learning), которое предполагает чередование очных и дистанционных занятий со студентами с применением инновационных ИКТ.

Данная методика получила достаточно глубокое описание в современной научной литературе (Г.А. Краснощёкова [3], Ю.Ю. Сайковская [5], И.В. Волосюк, В.Б. Казакевич [1]), однако её использование в образовательном пространстве российских вузов на данном этапе не характеризуется широтой распространения. Несмотря на многоголосицу учёных о неоднозначности перевода указанного термина на русский язык (гибридное обучение [4], смешанное обучение [1], комбинированный подход [3], комбиниро-
Перов Андрей Георгиевич К.т.н., дочент, Российский государственный университет правосудия, филиал Краснодар perov86@gmail.com

Аннотация: Настоящая статья призвана раскрыть особенности использования комбинированного обучения в среде российского вуза. Как инновационная модель обучения, предполагающая сочетание традиционных и новых подходов в иноязычном образовании, она показала свою эффективность в сегодняшних условиях. В статье проиллюстрированы возможности рассматриваемой методики, описаны возможные технологии её внедрения в образовательное пространство российского вуза. Автором работы сделан вывод 0 том, что комбинированное обучение может стать отправной точкой в дальнейшем реформировании языкового вузовского образования в России.

Ключевые слова:

комбинированное обучение, blended-learning, иностранный язык, неязыковой вуз.

ванное учение [5]), исследования последних лет свидетельствуют об эффективности применения принципов данной формы работы с учащимися при формировании комплекса всех компетенций и для развития навыков в области всех видов речевой деятельности на иностранном языке.

Среди несомненных достоинств данного подхода выявляется возможность комбинировать традиционные методики обучения языкам и инновационные, что является необходимым условием формирования у будущего специалиста навыка получения и обработки информации с использованием современных компьютерных технологий. Кроме того, данный подход представляет возможным интенсифицировать учебный процесс, что оказывается крайне необходимым при изучении курса «Иностранный язык» в вузе в современных условиях малого количества часов для освоения дисциплины в том объёме, которого требует ФГОС.

В методический потенциал комбинированного обучения входят несколько элементов, которые разнообразят образовательный процесс. Так, вслед за Е.В. Костиной определим те способы и формы работы с аудиторий учащихся при использовании техноло- 
гии Blended-learning в условиях современного вуза. В частности, это очные консультации педагога и студентов (face-to-face) в групповом, индивидуальном и коллективном формате (так называемые установочные лекции). Они нацелены на обсуждение наиболее сложных, проблемных вопросов, требующих большей концентрации (что не всегда достижимо при взаимодействии в дистантном режиме) и личной поддержки со стороны преподавателя. Заочные же встречи (электронное и дистанционное обучение (online learning) предполагают обсуждение полученных студентами результатов в ходе самостоятельной работы.

Следует отметить и тот факт, что при использовании средств комбинированного подхода представляется возможным реализовать принципы дифференцированного обучения. Симптоматично, что в рамках одного учебного коллектива находятся студенты, обладающие различным уровнем языковой подготовки. А учёт индивидуальных особенностей обучающихся, степени сформированности их стартовой базы помогает преподавателю грамотно выстроить процесс интеграции очных и заочных занятий. В частности, эффективным здесь оказывается метод проектов и популярная в последнее время методика перевёрнутого класса. На очных встречах с учебной группой преподаватель предоставляет учащимся установочные задания по самостоятельному нахождению и обработке необходимой иноязычной информации (с указанием различных ресурсов для учащихся со слабой языковой подготовкой, а также для самостоятельного поиска сведений для той категории студентов, чей уровень базовых знаний характеризуется как оптимальный или продвинутый).

При комбинированном обучении предполагается активное использование ИКТ для решения образовательных задач. Следовательно, то время, что запланировано для самостоятельной работы студентов, полностью интегрируется в цельный образовательный процесс, состоящий из очного и заочного взаимодействия пары «преподаватель-обучающийся». Из данно- го положения следует, что необходим кардинальный пересмотр концепции построения самостоятельной работы студентов: разведение понятий «самостоятельная» и «домашняя работа». Во время самостоятельной работы происходит полного погружение обучающегося в образовательный процесс. Например, в неаудиторный период студент просматривает специально подготовленные преподавателем (подкасты) и/или найденные им самим материалы (при условии необходимой дистанционной поддержки педагогом), а уже при взаимодействии в формате «face-to-face» выполняют письменные работы (собственные речевые произведения) на основе прочитанного, просмотренного, прослушанного (работа над формированием навыка иноязычного письма), проводят обсуждения, носящие дискуссионный характер (тренировка навыков говорения), зачитывают результаты проектной деятельности и т.д.

Сравнительная характеристика образовательных результатов студентов, достигнутых ими при традиционной форме преподавания дисциплины «Иностранный язык» и при переходе на комбинированное обучение, не показали значительной разницы в уровне сформированности иноязычных компетенций, о чём свидетельствуют итоги проведения экзаменационных мероприятий, срезовых и контрольных работ. Следовательно, данную методику в сфере иноязычного образования представляется определить как одну из эффективных.

Справедливости ради отметим, что данный подход достаточно глубоко проник в модель обучения у зарубежных коллег [6] и предполагает большую роль самостоятельности со стороны студента, что не всегда реализуется в системе российского образования. Blended-learning, с нашей точки зрения, как инновационная (а в сегодняшней ситуации и необходимая) методика обучения может стать тем переходным, адаптационным этапом, который поменяет вектор российского образования, переведя его на новый уровень.

\section{ЛИТЕРАТУРА}

1. Волосюк И.В. Использование моделей смешанного обучения в вузе как необходимое условие методической и предметной компетентности преподавателя иностранного языка / И.В. Волосюк, В.Б. Казакевич // Предметная и методическая компетентность как важнейшая составляющая профессионального мастерства преподавателя иностранного языка: материалы Il общеуниверситет. семинара (Минск, 26 марта 2015 г.) / Белорус. гос. пед. ун-т им. М. Танка; редкол.: А.В. Торхова [и др.]; отв. ред. В.П. Скок. - Минск: БГпУ, 2015. - С. 36-41.

2. Костина Е.В. Модель смешанного обучения (Blended Learning) и её использование в преподавании иностранных языков / Костина Е. В. // Известия высших учебных заведений. Серия: «Гуманитарные науки». - 2010. Т. 1. - № 2. - С. 141-144.

3. Краснощёкова Г.А. Модернизация системы языкового образования магистров технических вузов / Г.А. Краснощёкова // Современные проблемы науки и образования. - 2017. - № 6. - URL: http://www.science-education.ru/ru/article/view?id=27164 (дата обращения: 24.11.2020).

4. Остапенко А.С. Гибридное обучение: новые возможности при обучении иностранному языку в школе / А.С. Остапенко // Вестник Тюменского гуманитарного университета. Серия: Гуманитарные исследования. - 2017. - № 3. - С. 270-279. 
5. Сайковская Ю.Ю. Комбинированное учение как средство развития умений иноязычного полилогического общения / Ю.Ю. Сайковская // Вестник МГЛу. Серия 2: Педагогика, психология, методика преподавания иностранных языков. - 2017. - N 1(31). - С. 98-107.

6. Rooney J.E. Blended Learning Opportunities to Enhance Educational Programming and Meetings / J.E. Rooney // Association Management. - 2003. - N 55. - pp. 26-32.

○ Перов Андрей Георгиевич (perov86@gmail.com).

Журнал «Современная наука: актуальные проблемы теории и практики»

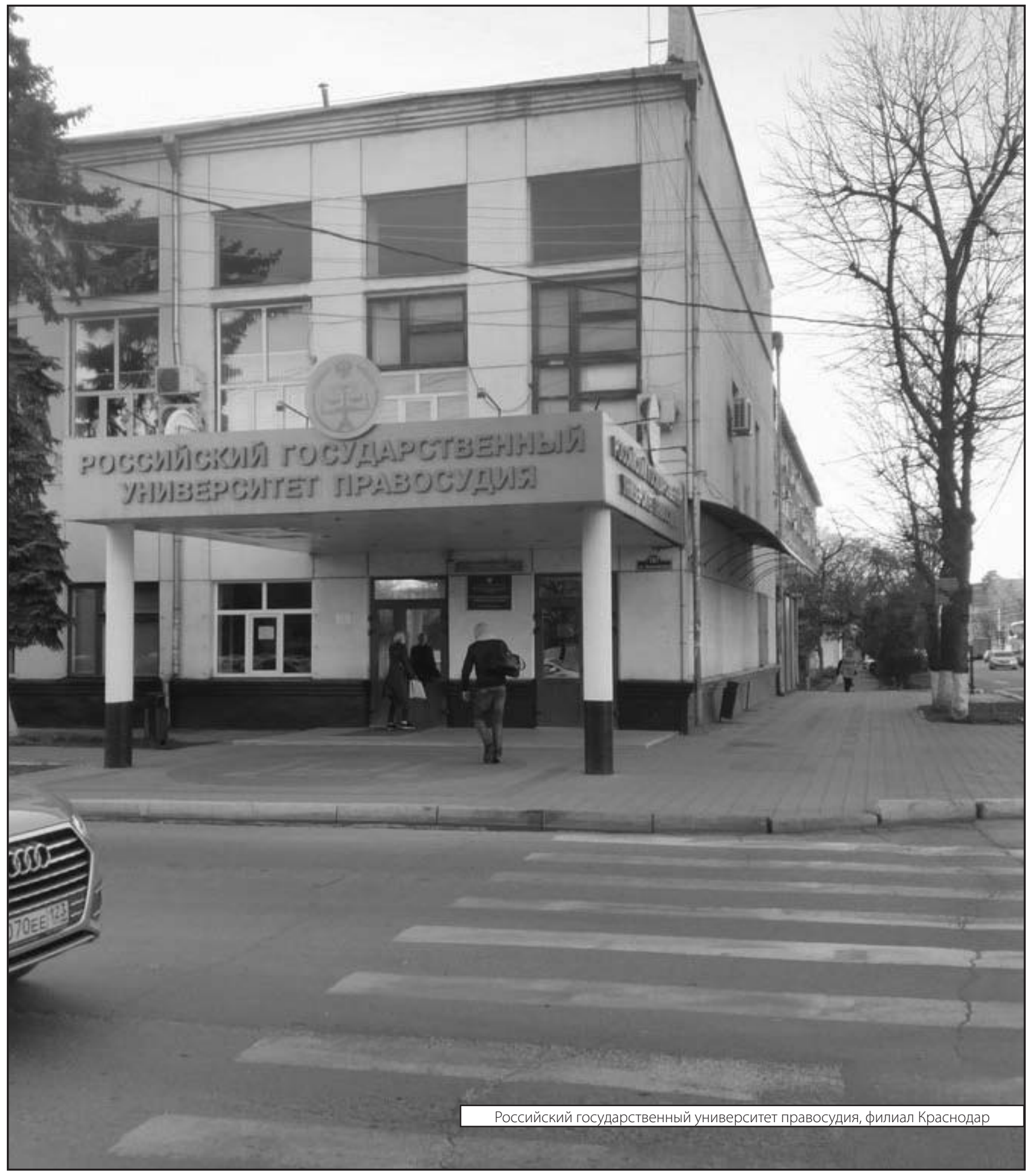

